\title{
Population Traits and a Female Perspective for Aglae and Exaerete, Tropical Bee Parasites (Hymenoptera, Apinae: Euglossini)
}

\author{
David W. Roubik \\ Smithsonian Tropical Research Institute, Apartado Postal 0843-03092, Panamá, Panama \\ Correspondence should be addressed to David W. Roubik; dwr2007david@gmail.com
}

Received 8 January 2019; Accepted 31 March 2019; Published 2 May 2019

Academic Editor: G. Wilson Fernandes

Copyright (c) 2019 David W. Roubik. This is an open access article distributed under the Creative Commons Attribution License, which permits unrestricted use, distribution, and reproduction in any medium, provided the original work is properly cited.

Size variation of both males and females leads to taxonomic confusion regarding wholly parasitic euglossines. The six most widespread species, Exaerete frontalis, E. smaragdina, E. dentata, E. trochanterica, E. lepeletieri, and Aglae caerulea, ranged from 12.5 to $28 \mathrm{~mm}$ in length ( $\mathrm{n}=522 ; 50$ females; 472 males), and within species, some were $40-80 \%$ larger than others. The size of E. lepeletieri matches E. smaragdina and E. dentata, but not E. frontalis, which it was said to resemble. Female E. lepeletieri, here described from Amazonian Ecuador, has a range shown to also include French Guiana and Suriname. Female Aglae and Exaerete were larger than males. Statistically, female Exaerete tended toward larger individuals more than did males. Each species should parasitize Eulaema and Eufriesea that have comparable size and provisions; thus multiple hosts may cause parasite size variation. Unknown factors may promote host resource partitioning between sympatric parasites, which include up to six in Yasuní Biosphere Reserve, Ecuador, the richest known euglossine community. Scutellum and metafemur punctation, sculpture and the frontal knob of both sexes, and male mesotibial tuft and metafemur permit easy identification of the six common species and $E$. azteca. Existence of E. kimseyae in Panama is questionable, while E. dentata there is certainly rare. The female tibial scoop, a structure in both Aglae and Exaerete, with a proposed function in material transport, is discussed. No new phylogenetic interpretation is presented.

\section{Introduction}

Euglossines have two parasitic genera. Those bees, Exaerete Hoffmannsegg and Aglae Lepeletier and Serville, became their present taxonomic genera well after the first species were described, and there is insight to be gained in their analysis. Predominantly South American distributions include the nine species now recognized. Seemingly contrary to the ecological rule that parasites are less abundant compared to their hosts, Linnaeus, 1758, described both the first cleptoparasitic euglossine, from Trinidad, now known as Exaerete dentata (Linnaeus), and also one of its hosts, Eufriesea surinamensis (Linnaeus), under the genus Apis Linnaeus, 1758. Later, the second host genus, Eulaema (Olivier) [1], was described, as an Apis, in 1789 [1-3]. Aglae caerulea from the forests of French Guiana was described in 1825 by Lepeletier and Serville, and a known host is a Eulaema [4].
Repeated observations confirm the parasitism of Eulaema and Eufriesea Cockerell by the bees treated here [3, 4]. Interestingly, when Kimsey [2] formulated a key to Exaerete males and females, most of the wholly parasitic euglossines had been described from females (A. caerulea, E. trochanterica (Friese), E. smaragdina (Guérin), E. frontalis (Guérin), and $E$. dentata (Linnaeus)). That tendency-for females to become the species holotypes-has since discovery of chemical baits for males been completely overturned [3]. Males, in many earlier works yet still today, are inadequately known, in part, because they could never become "type" specimens. That would normally require that they were formally described and further matched as progeny from the same nest or female of a certain species and also included in the first taxonomic description. Another reason is that they were less likely to be taken by collectors. The type females were probably most often collected while parasitizing the aggregated, exposed 
nest cells of Eufriesea, or certain Eulaema on manmade structures (Supplemental Figure S1). Males visited nectar flowers and mating sites but were otherwise less often seen, except at a mating perch. The fact that Aglae was described well after Exaerete agrees with my observation that this genus is found primarily within forest, not near buildings or townsites. It is perhaps rare but is easily heard, as it makes a clacking sound during flight.

The large size and striking metallic color of parasitic euglossines continue to draw the attention of collectors, naturalists, and photographers. However, the secluded nests of most Eulaema and Eufriesea $[3,5]$ made their interaction with Aglae and Exaerete difficult to observe, and their taxonomy has been slower to develop [1]. The phylogenetic position of the cleptoparasites is still debatable [6,7]. Classical taxonomy seems unable to deal with the phylogenetic question, while gene fragments suggest Aglae and Exaerete diverged from a common ancestor in the Oligocene, roughly 28 mya, after which related taxa have gone extinct, leaving gaps in any reconstructed phylogeny [6].

Host bees of cleptoparasitic euglossines, evidently not including large Glossura or Glossuropoda Moure (groups in Euglossa), which are as large as many Eufriesea and mimic them, remain poorly documented, as is their biology [3]. Intraspecific parasitism, involving egg eating within nests, seems quite common in Euglossa [3, pp. 62-68] indicating how a strict parasite genus likely evolved. However, within Euglossini there are no cleptoparasitic species within otherwise nonparasitic genera, as there are in Bombus Latreille [3]. In addition, Exaerete kimseyae Olivera is known from a single specimen [8], found on Barro Colorado Island, Panama, verily within the most intensively sampled euglossine region [3, 9-11]. Intensive study and baiting of males there have not produced any more of this species (see Discussion and Conclusion). As summarized in Engel [7] recognition of such apparently endemic species, new synonymies and new interpretations are still possible.

The purpose of this paper is to solve taxonomic problems and describe an additional female of wholly cleptoparasitic Euglossini. With one abundant western Amazonian species I found size traits made it difficult to identify. It was considerably smaller than $E$. frontalis, claimed to be of a similar size [12]. One does see size variation within the parasitic euglossine species in museum collections. A visit to the State of Florida Arthropod Collection, Gainesville, Florida, at the Division of Plant Industry, allowed me to examine series of Exaerete and Aglae. Combined with other specimens of my own collections, male and female size data were compiled. Here I examine the six most abundant and widespread obligately parasitic euglossines: Exaerete frontalis, E. trochanterica, E. smaragdina (Guérin), E. lepeletieri Oliveira and Nemésio, E. dentata, and Aglae caerulea. A tabulation of diagnostic traits, adding high definition photographs to definitive work advanced by Kimsey [2], provides an aid to identification of both males and females. Implications of size variation and a newly recognized female trait for euglossine specialist cleptoparasites are also introduced.

\section{Materials and Methods}

Histograms were plotted for bee size distribution. Male and female bees were measured in total length in their normal position mounted on insect pins in dry storage cabinets. A bee was examined from the side, holding a ruler parallel to the long axis of its body. The tip of the abdomen and head were viewed, and the specimen was measured to the nearest 1.56 $\mathrm{mm}\left(1 / 16^{\text {th }}\right.$ inch). More exact, microscopic measurements were not deemed useful, because the inclination of the head and position or elongation of the metasoma influence length, although likely few $\mathrm{mm}$ from "true" size. I tried to compensate for the extreme cases of metasomal position. Therefore, 10 discrete size categories were used to measure bees, ranging from nine to 18 sixteenths of an inch (14-28 $\mathrm{mm}$ ). The female specimens displayed tubular projection of terminal metasoma of approximately 1.0 to $1.5 \mathrm{~mm}$. That was included in measurements but a protruding sting was not. The mode, mean, and range were computed from body length data. Males and females were tabulated separately. Despite small sample sizes for Exaerete azteca Moure (supposedly restricted to Mexico) and E. trochanterica (described from eastern Amazonia in Belém and found also in western Amazonia), as they were of considerable interest here, the data are included in the Results. Other species were sampled from several localities through their range in lowland tropical America. Aglae does not exist north of Colombia and has never been found in Panama, yet it is common in French Guiana and the western Amazonian lowland forests, while E. kimseyae, being detected only once, on an island in the Panama Canal, may well have its record there due to being transported on a ship in containers or aboveboard contents, from a Latin American port of unknown locale.

Taxonomic traits were examined considering external diagnostic features useful for euglossines, in general, including various metrics $[3,5,13,14]$. The genital capsule of $E$. lepeletieri was examined from six males collected in lowland Amazonian Ecuador by the author and from one male kindly provided by M. L. Oliveira from Roraima, Brazil. Females of that species were distinguished from those of sympatric E. smaragdina in Yasuní Biosphere Reserve, Ecuador (from which most sampled individuals came), and further verified by comparison to females from Costa Rica and Panama, where E. lepeletieri is absent. For study of male terminalia, metasomal segments were removed from pinned museum specimens, softened by rehydration with eugenol (clove oil) added as a fungal retardant, placed in $10 \%$ cold $\mathrm{KOH}$ solution for a few days, and then cleaned using watchmaker's forceps, rinsed in dilute ethanol, and preserved in glycerol in a small polyethylene genitalia vial (Bioquip, California). Photomicrographs of bee specimens employed image stacking using Helicon-Pro software, the Canon EOS DS Mark III with four external flashes, a white acetate image box with a movable stage and black velvet background, and the 5x MP-E 65 $\mathrm{mm}$ Canon Macro Photo Lens. Photographic images were taken in sets of 80-120 stacking layers. Postcapture image edits-the removal of particles or fibers, the insect pin, and adjustment of the background-were done using Adobe Photoshop. 
TABLe 1: Size in male and female parasitic euglossines, Aglae and Exaerete. Sample areas were Brazil, Panama, Suriname, French Guiana, Peru, Ecuador, Costa Rica, Mexico, Trinidad, Venezuela and Colombia. * Males given first in Table cells.

\begin{tabular}{|c|c|c|c|c|c|c|c|}
\hline $\begin{array}{l}\text { Male and Female } \\
\text { traits* }\end{array}$ & E. azteca & E. dentata & E. lepeletieri & E. smaragdina & E. frontalis & E. trochanterica & A. caerulea \\
\hline Mean Length (mm) & $\begin{array}{c}15.6, \mathrm{n}=4 \\
\mathrm{~N} / \mathrm{A}\end{array}$ & $\begin{array}{l}17.4, \mathrm{n}=7 \\
17.8, \mathrm{n}=17\end{array}$ & $\begin{array}{c}17.5, \mathrm{n}=65 \\
19.2, \mathrm{n}=3\end{array}$ & $\begin{array}{c}18.3, \mathrm{n}=212 \\
20.1, \mathrm{n}=15\end{array}$ & $\begin{array}{c}22.8, \mathrm{n}=140 \\
25.2, \mathrm{n}=8\end{array}$ & $\begin{array}{c}23.4, \mathrm{n}=10 \\
22.3, \mathrm{n}=1\end{array}$ & $\begin{array}{c}21.9, \mathrm{n}=34 \\
22.6, \mathrm{n}=6\end{array}$ \\
\hline Mode Length (mm) & $16.2 ; \mathrm{N} / \mathrm{A}$ & $17.1 ; 18.7$ & $17.2 ; 19.2$ & $17.2 ; 20.3$ & $23.4 ; 25.0$ & $23.4 ; 22.3$ & $22.6 ; 25.0$ \\
\hline Length Range (mm) & $\begin{array}{c}15.6-19.0 \\
\text { N/A }\end{array}$ & $\begin{array}{c}16-19 ; \\
12.5-20.3\end{array}$ & $\begin{array}{c}15.6-21.8 \\
17.1-21.8\end{array}$ & $\begin{array}{l}14.0-21.8 \\
14.0-21.8\end{array}$ & $\begin{array}{c}15.6-28.1 \\
21.8-28.1\end{array}$ & $23.4-26.0$ & $\begin{array}{l}15.6-26.5 ; \\
18.7-25.0\end{array}$ \\
\hline
\end{tabular}

TABLE 2: Diagnostic traits for species identification with the microscope. Sampling area as in Table 1.

\begin{tabular}{|c|c|c|c|c|c|c|c|}
\hline Trait & E. azteca & E. dentata & E. lepeletieri & E. smaragdina & E. frontalis & E. trochanterica & A. caerulea \\
\hline frontal knob $*$ & & + & + & + & ++ & & \\
\hline internal meta-femoral knob & & & & & ++ & & \\
\hline external meta-femoral knob & ++ & ++ & & & & ++ & \\
\hline scutellar smooth area $*$ & & & + & ++ & + & +- & \\
\hline scutellar trough $*$ & + & ++ & & & & ++ & \\
\hline scutellar median welt* & & & + & + & + & & \\
\hline slender hind tibia* & & & & & & + & + \\
\hline bluish color throughout* & $\begin{array}{l}\text { Blue green to } \\
\text { purple }\end{array}$ & $\begin{array}{c}\text { Green to } \\
\text { bluish purple }\end{array}$ & & & & & ++ \\
\hline *also in female & & & & & & & \\
\hline
\end{tabular}

\section{Results and Discussion}

3.1. Bee Size. Table 1 and Figure 1 contain size information for male and female bees and regions from which material was studied. Sampling from within much of their geographic range and also within a single spot (see further, below) revealed considerable size variation. A size variability of 40$80 \%$ was found among the five species with relatively large samples, and four to nine size classes. Of the large and relatively well sampled parasites, E. frontalis and A. caerulea, large individuals were $70-80 \%$ longer. The sample size of male E. trochanterica and E. azteca was limited, and bees, particularly the former species, varied relatively little in size. Among females, size was 50-60\% greater in some specimens, although samples were few for all but E. dentata and $E$. smaragdina (Figure 1). However, even considering widely differing sample sizes of the sexes, the range was similar in male and female E. smaragdina and E. lepeletieri. Nearly the entire sample of E. lepeletieri, except for one individual, came from the $8 \mathrm{~km}^{2}$ area of the Yasuní Scientific Station (other males were noted from Suriname and French Guiana, but not measured). For comparison, the wet mass of "empty" E. frontalis males was given for 11 bees, collected on the same day in Panama [15]. They weighed a mean of $612 \mathrm{mg}$, with the largest $41 \%$ heavier than the lightest (695/494 mg). Considering bee lengths, the mode sizes, i.e., the typical individuals for a population, were very similar for the large bees, Aglae, E. trochanterica, and E. frontalis and for E. dentata, E. smaragdina, and E. lepeletieri. Females were 1.6$2.0 \mathrm{~mm}$ longer than the males of their species and differed slightly more among them.
Why does size vary and why might this matter? Different host species likely have different provision quantity or even quality, which must affect parasite larval development and adult size. A parasitic species with greater size variation might therefore use more host species (see also below). Notably, the males tended to have a symmetrical size distribution, with a peak near the middle, while the two females with sufficient data did not display this trait. The reason or validity of this contrast remain obscure. The altitudinal range of parasite species is another factor, due to the sometimes larger variety of Eufriesea and Eulaema in highlands compared to lowlands [3].

3.2. Species and Gender Traits. Table 2 provides diagnostic features for both genders. Bees and morphology are depicted in Figures 2-8 and Supplemental Figures. Details on the female and male of E. lepeletieri are given below.

Female Exaerete lepeletieri $(\mathrm{n}=3)$ collection data: "ECUADOR ORELLANA, YASUNI $250 \mathrm{~m}, 00^{\circ} 56^{\prime} \mathrm{S}, 75^{\circ} 24^{\prime} \mathrm{W}$ 30 AUG 1998, C. Skov, second label QCAZ I, 20063"; "ECUADOR NAPO, Archidona 600 Metros, $77^{\circ} 50^{\prime} 00^{\prime \prime} \mathrm{LW}$ $00^{\circ} 55^{\prime} 00^{\prime \prime} \mathrm{LS}, 03 / 06 / 2001$ Mónica Reinoso"; "ECUADOR ORELLANA, CS YASUNí $250 \mathrm{~m}, 00^{\circ} 56^{\prime} \mathrm{S}, 75^{\circ} 24^{\prime} \mathrm{W} 17$ OCT 1998, C. Skov, label Exaerete smaragdina (handwritten, black ink) det. David W. Roubik 1998, third label “QCAZ I45”.

Morphological Details. Light metallic green, like male. Less often bluish green to blue on basal 1/2 mandible, labrum, clypeus, scape; bluish highlights, subject to light and angle. Mandible tridentate, inner two denticles of similar size 

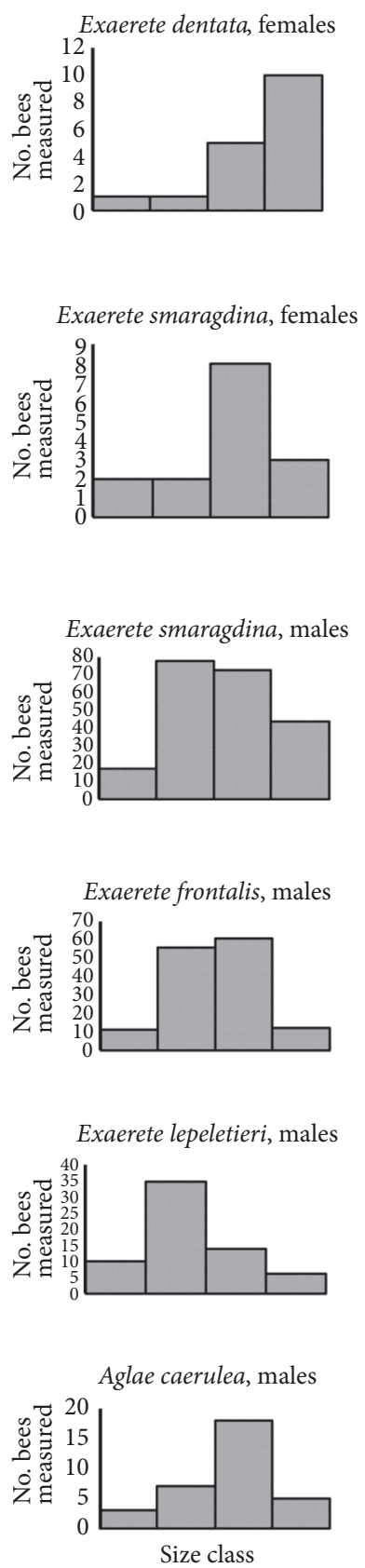

FIGURE 1: Frequency histograms showing size distributions of parasitic euglossine adult females and males. Measurements usually converted from inches to $\mathrm{mm}$; size categories combined here, for uniformity across species (see Methods); measurements and statistics given in Table 1 .

(male bidentate, inner denticle large). Clypeus more bulging, median impunctate strip narrower, compared to male. Head $10 \%$ narrower than that of similar sized male. Like male, frontal knob, lateral scutellar, and hypoepimeral knobs developed, the first, as with the male, polished medially and similar in size to the interscrobal knob. Metafemur lacking knob or projection near the basal inner $1 / 3$, similar to male, having a submedian outer edge projection followed by seven to nine short denticles. Wing coloration and vestiture uniformly brownish, like male. Punctation sparse along transverse median scutellum, sometimes invaded anteriorly by smaller pits, generally having larger, widely separated pits across the scutellum, between the scutellar knobs (see Figure 3; Table 2).

Body Length 17.1-21.8 mm

Headwidth 5.12-5.43 mm

Forewing length $16.5-19.8 \mathrm{~mm}$

Intertegular distance 4.11-4.65 mm

Mesotibia, length, and width 3.1-3.72 x 1.00-1.32 mm

Mesobasitarsus length 2.9-3.57 mm

Metatibia length \& width $5.58-6.35$ x 1.86-2.17 mm

Metabasitarsus, length \& width $3.1-3.41 \times 1.09-1.24$ $\mathrm{mm}$

Metatibial scoop, length \& width $0.62-0.78 \times 0.78-$ $1.09 \mathrm{~mm}$

Hamuli 38-39

Jugal hairs 10

Folded proboscis barely reaching S3

The female may be distinguished from female E. smaragdina and E. dentata not by size (Tables 1 and 2; Figure 4) but by the scutellum. Scutellar pit arrangement and density are clearly distinctive in both genders of the three species. Exaerete dentata has a more or less even distribution of medium sized pits, and a conspicuous scutellar trough, with no median welt or elevation. Both male and female smaragdina have a pronounced median scutellar strip, polished and having sparse pits of medium size and a large median welt. In contrast to smaragdina and lepeletieri, the hypoepimeral knob of female dentata is weakly developed, but slightly more than on the male. The small frontal knob of all three smaller Exaerete is quite similar. The distal medial welt of the scutellum bulges notably in both lepeletieri and smaragdina.

The male genital capsule, taking a specimen provided from Roraima, Brazil, and identified by M. Oliveira, compared to collections in Yasuní Scientific Station, Francisco de Orellana Province, Ecuador, showed no noticeable difference. Long hairs arise in the central S7 toward its straight terminus, and in patches at the lateral distal $1 / 3$. It is somewhat difficult to appreciate the structure from a drawing given by Oliveira and Nemésio [12]. Depending on the angle viewed, the form of S7 that rests upon the genital capsule is quadrate, with meagre lateral lobes, and a central small lobe with a median indentation, heavily hirsute.

At species level, the identification of Aglae and Exaerete is straightforward. The taxonomic and possible phylogenetic importance of the male mesotibial tuft should not be understated, as past authors [e.g., $[7,8,12]]$ have chosen to do. Those of dentata and trochanterica are very close, with a hirsute area or extended tibial tuft along the mesotibia for nearly half its length, on a margin of the velvet area. Those of frontalis and lepeletieri are similar, and the tuft is eyebrow-like, and scarcely visible when viewed straight on, while in oblique views it can be seen to extend and gradually taper along a low ridge on the mesotibia, about one-third its length. In these two species 

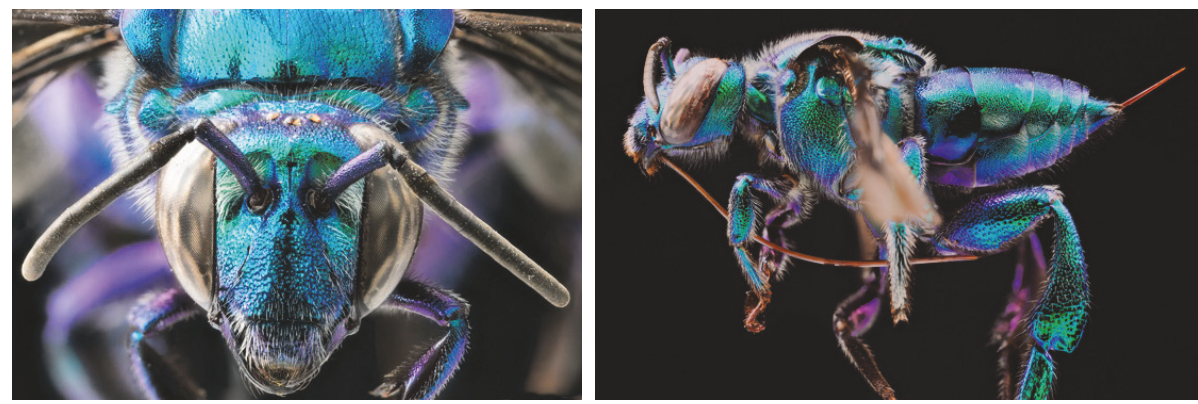

Figure 2: Female habitus and face of Exaerete lepeletieri.

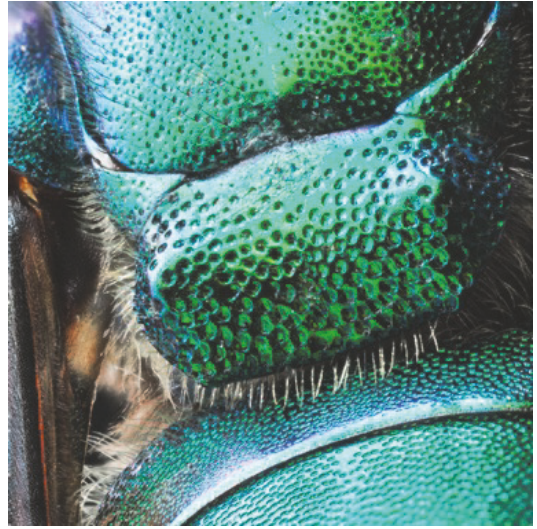

(a)

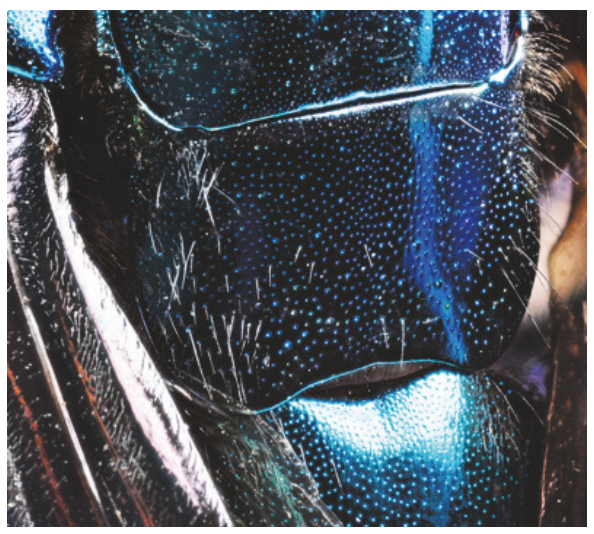

(d)

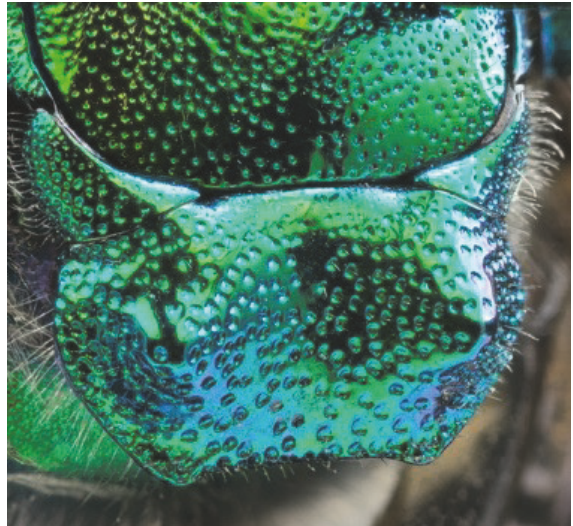

(b)

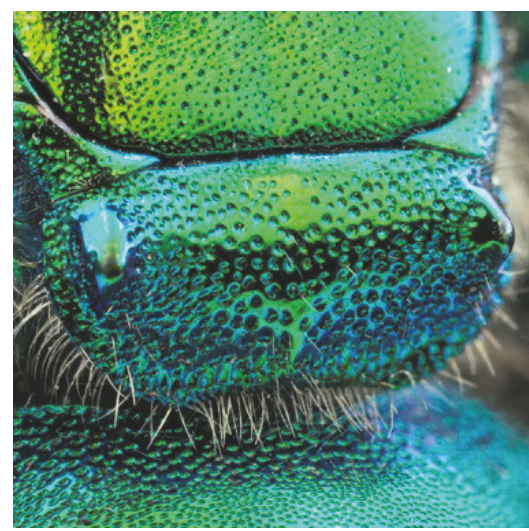

(e)

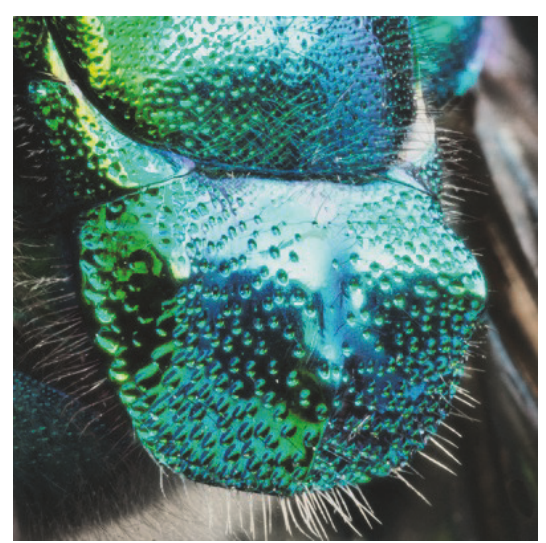

(c)

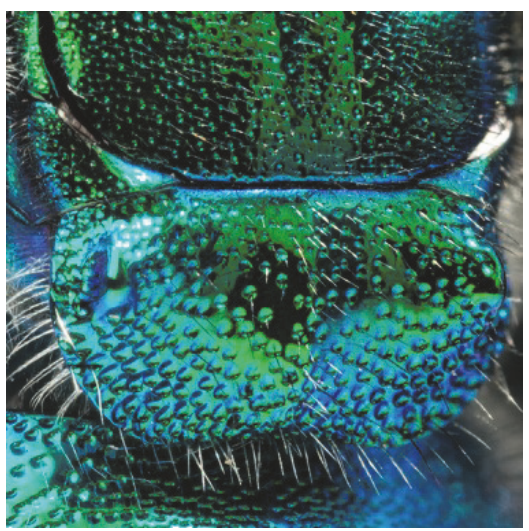

(f)

Figure 3: Male scutellum (also applicable to females) of parasitic euglossines. (a) E. dentata; (b) E. trochanterica; (c) E. smaragdina; (d) A. caerulea; (e) E. frontalis; (f) E. lepeletieri.

alone there is a greenish luster of the entire outer mesotibia and velvet area. Exaerete smaragdina, in contrast, has a rather short, triangular wedge of blackish and long hair at the base of the mesotibia, which is mostly dark brownish.

As indicated in Tables 1 and 2, the largest species are Aglae, E. trochanterica, and E. frontalis. Exaerete trochanterica has a rounded head and large vertex, in addition to other characteristics noted in Table 2 . However, especially including E. azteca and E. dentata, the adult size or even color, due to variation, are sometimes insufficient as primary identifiers. The various knobs of $E$. frontalis, one on the male and female frons, two on the scutellum, and one on the male metafemur, exclude the other taxa (Figures 3 and 5). Likewise, the enormous male metafemoral tooth on the outer surface (Figure 6) and the evenly pitted, troughed scutellum of both male and female E. dentata exclude other species, although E. trochanterica and male E. azteca (see Table 2) also have the scutellar trough (Figure 3). Exaerete trochanterica and A. caerulea have long and slender metatibiae and metatarsi, but the latter is a steely bluish color and has a unique scutellum (Figures 3 and 6; Supplemental Figure S2). The extent of the glossa, beyond the buccal feeding complex, 


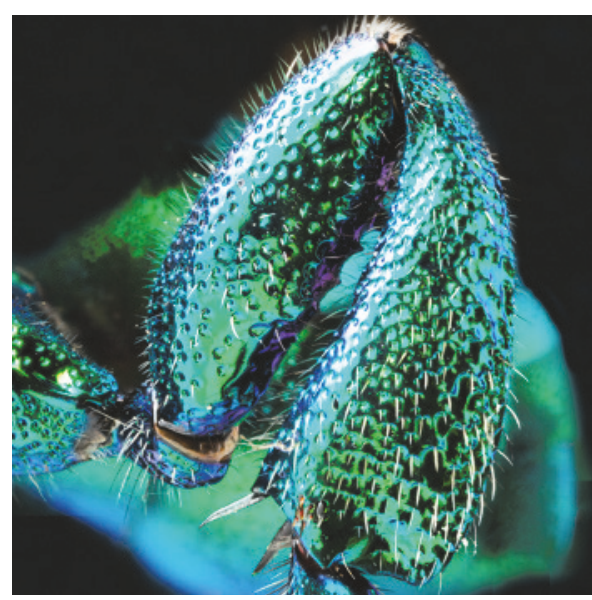

(a)

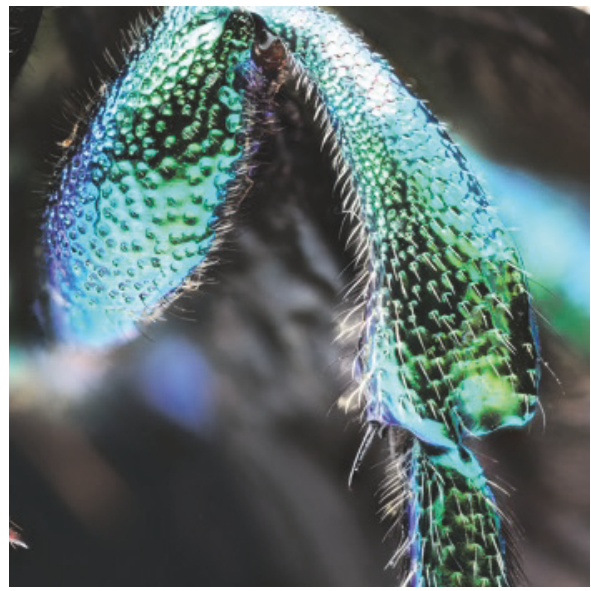

(c)

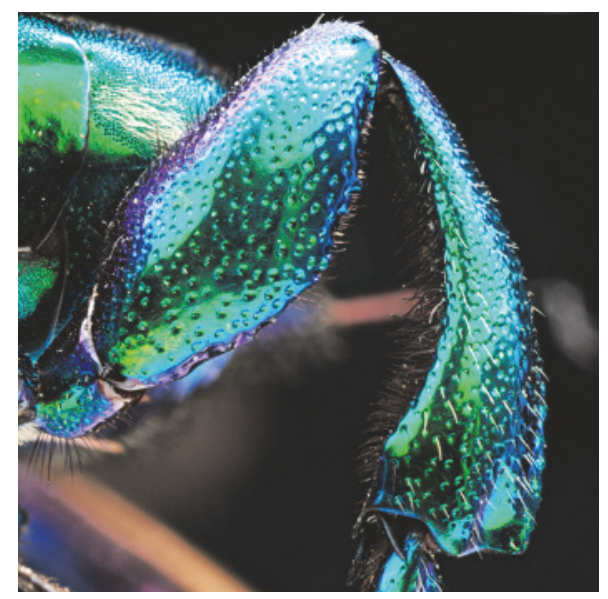

(b)

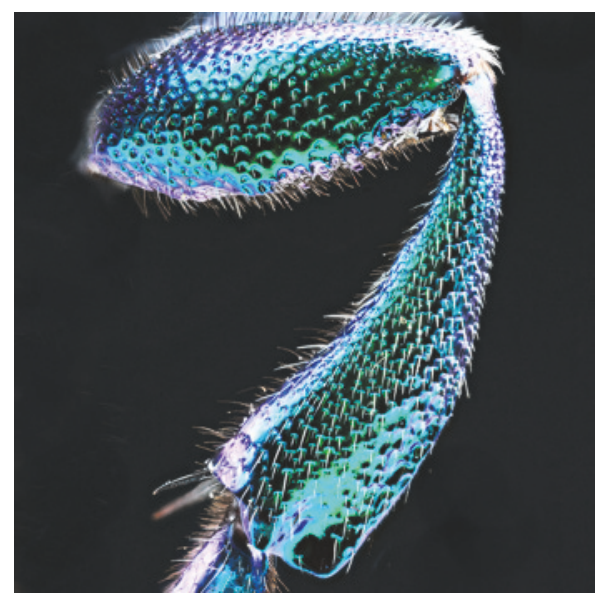

(d)

FIgURE 4: Female hind legs of parasitic euglossines. (a) E. dentata; (b) E. lepeletieri; (c) E. frontalis; (d) E. smaragdina.

is also impressive in A. caerulea (Supplemental Figure S2). The strikingly similar mesotibial tufts of E. lepeletieri and $E$. frontalis are useful to immediately separate those species from others. In conjunction with the abovementioned knobs and the differing scutellar punctuation, they permit identification and separation from E. smaragdina, for both sexes (Figures 3 and 8). There is an error which I made in 2006, given on "discoverlife.org", in which the male of E. lepeletieri is given as an example of E. dentata in French Guiana. Combined with the images given here, both the male and female of $E$. lepeletieri are perhaps the most readily viewed and verified of the genus. For the six most widespread parasitic euglossines, and E. azteca, a taxonomic name for male or female is here readily obtained.

Presence of a smooth pit near the apex of the female's outer metatibia, which I call a tibial scoop, is nearly half its maximum width in both Aglae and Exaerete (Figures 5 and 7). It resembles a corbicula and is polished, with a few long hairs within. Because parasitic bees never collect pollen at flowers, the structure, hairs, and presumably behavior associated with pollen manipulation are lost during evolution [16]. I suggest the scoop may be used with host nest material or as an aid in parasitism. The only building material which a female might use would be as a mason of host cells. Exaerete frontalis, for example, observed in host nest hives of Eulaema meriana (Olivier) in Panama, chews open a large hole in the hard mud brood cell of Eulaema. After it is parasitized, the cell is again sealed with mud by the adult female parasite, and she may stay for several days, forage occasionally, and guard her cell or cells from other Exaerete (unpublished, DWR and A. Parra, see also [4]). We have no further details, so that more observation is necessary. In the absence of active mud foraging by females, which has never been witnessed, the tibial scoop may be used to transport mud within the host nest, or even resin or pollen provisions. I found small residues of pollen within the tibial scoop of one female E. frontalis, near a host nest in Panama. It seems that a long, slender hind leg might also be used, by the female parasite at a potential host cell, to explore or manipulate the cell contents, including destroying an immature bee. Because both Aglae and Exaerete parasitize the mud cell nests of Eulaema their behavior within nests, using the scoop and hindlegs, may be quite similar, but such a study has not been made. For the larger potential host species of Eufriesea the nest structure and contents are 


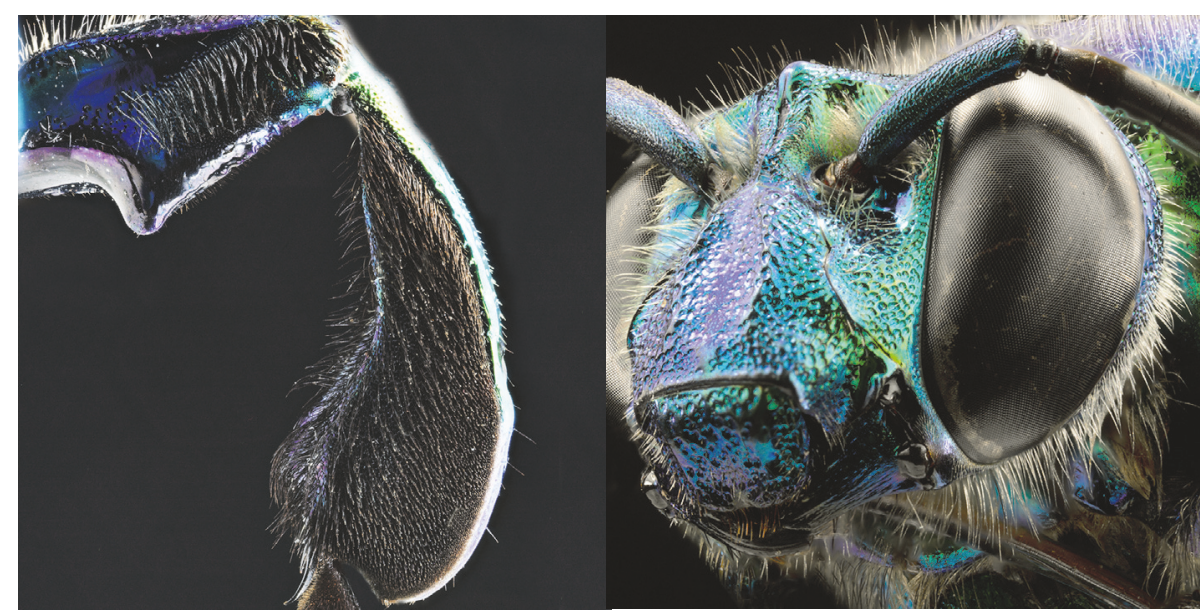

Figure 5: Male hindleg, notably femur (inner view) and head, E. frontalis.

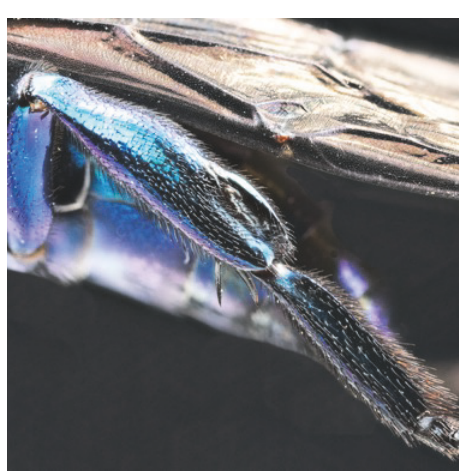

(a)

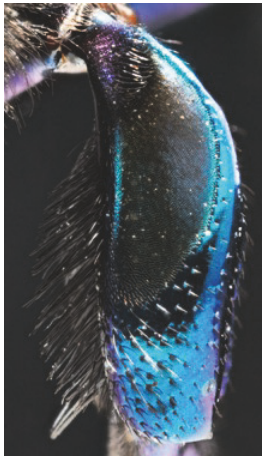

(b)

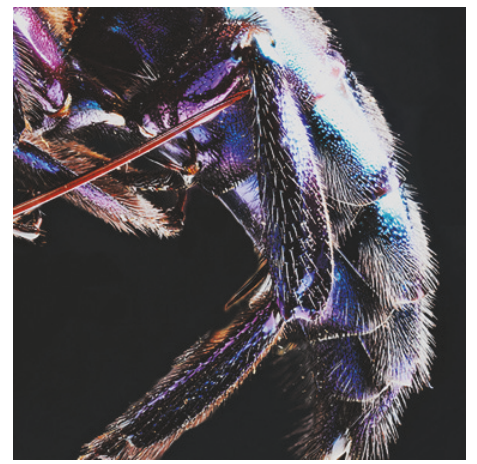

(c)

Figure 6: Male A. caerulea, (a), (b), lateral view of hindleg and mesotibial tuft; (c) female, lateral view, showing metatibial scoop.

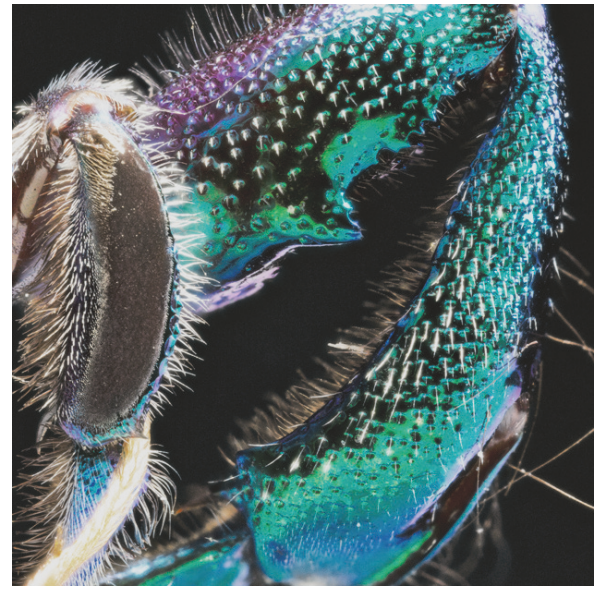

(a)

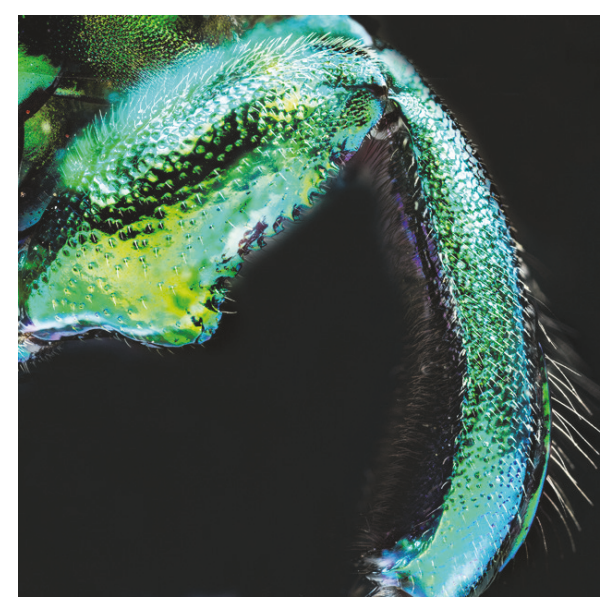

(b)

FiguRE 7: Male hind legs of parasitic euglossines: (a) E. dentata; (b) E. trochanterica.

presumably wood and resin but may also contain mud. It is possible that euglossine parasites carry resin or reuse some of the nesting material, within the nest of Eufriesea, with their hind tibia.
Exaerete dentata is familiar from few specimens in Panama, collected by R. L. Dressler in 1968. Two females, seen by the author, were within the "Canal Zone" at approximately 45 masl, and the male in the forest of Cerro Campana 


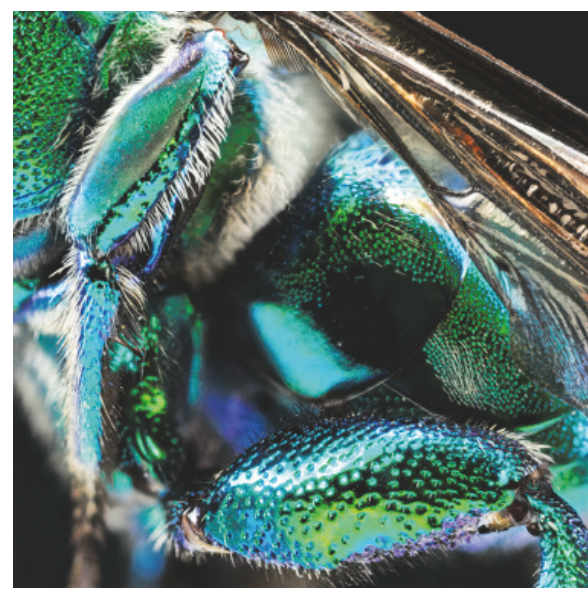

(a)

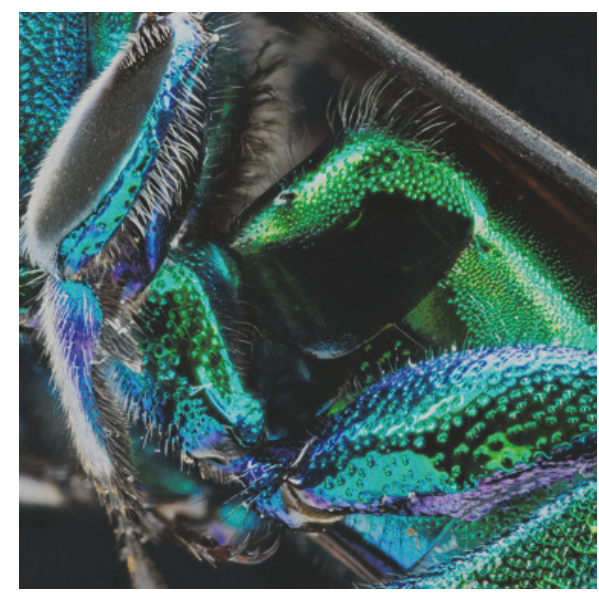

(b)

FIGURE 8: Male legs of parasitic euglossines: (a) E. lepeletieri; (b) E. smaragdina.

National Park, at nearly 900 masl (deposited in the State of Florida Arthropod Collection and at STRI, DWRoubik collection). Despite working a bee monitoring program at each site and additional protected areas since 1979, I have not baited a single male $E$. dentata at cineole, methyl salicylate or skatole $[10,11,17]$. The individual male caught by R. L. Dressler was attracted using "piperonal" (written on a label with the specimen) which is very rarely used in bee field study.

\section{Conclusion}

Rarity in conjunction with diversity is a common theme in tropical biology [16] and key bee parasites are scarcely known. This study gave a sample of size variation and traits that identify six common euglossine interspecific (and presumably intraspecific) cleptoparasites in tropical America. The female of E. lepeletieri is described, and the trait of female "tibial scoops" on the outer metatibia of both Aglae and Exaerete is discussed.

Obligately parasitic euglossines are relatively few, but their local number is easy to underestimate. However, the individual male registered first as E. trochanterica and now as E. kimseyae was collected on Barro Colorado Island Nature Monument [2]. Because hundreds of E. frontalis have been recorded in that area during programmed 40-year-long studies totaling over 1000 person-hours (see $[3,18]$ ), it is unlikely another large Exaerete exists there, only the smaller E. smaragdina and E. dentata. Among larger Exaerete, the E. trochanterica group has a relatively long vertex and rounded head, scutellar knobs much closer together, and a slender hindleg [6-8], compared to the morphologically unique $E$. frontalis (Figures 4 and 5). The trochanterica group is not readily confused with $E$. frontalis of any size. Because $E$. dentata is present from South America to Central America [2], and the material studied included Trinidad, Panama, Ecuador (Guayaquil), Peru (Tingo Maria), and Brazil (São Paulo) and has been recently found in Belize (S. Javorcek, pers. comm.), then it can certainly be added to the parasitic bee fauna of the Amazonian Yasuní Biosphere Reserve, which, like many organisms, contains the highest diversity known anywhere $[19,20]$. It is by any standard a rare bee. In the Yasuní Scientific Station forest, maintained by PUCE (Pontífica Universidad Católica del Ecuador), there are likely six wholly cleptoparasitic euglossines: E. frontalis, E. trochanterica, E. smaragdina, E. lepeletieri, E. dentata, and A. caerulea, active all year, with at least a dozen potential euglossine hosts of Eulaema and Eufriesea. They may also each invade and "hyperparasitize", i.e., parasitize the parasite, within host nests. Such details will be interesting, when discovered.

\section{Data Availability}

The data used to support the findings of this study are included within the article.

\section{Conflicts of Interest}

The author declares that they have no conflicts of interest.

\section{Acknowledgments}

For help at DPI in Gainesville I thank W. C. Whitehill, E. Talamas, P. Skelley, and M. Whitten, and for work in Ecuador especially at PUCE at MCAZ I thank F. Maza, A. Argoti, E. Baus, and R. Jarrín. This paper is dedicated to the memory of our friend Dr. Mark Whittten.

\section{Supplementary Materials}

Figure S1: the nest aggregation of Eufriesea, likely surinamensis, on a concrete structure, showing one host bee and a female of parasite Exaerete smaragdina (photograph 
by G. Gerlach). Figure S2: a female Aglae caerulea showing the extended glossa and large overall tongue length. (Supplementary Materials)

\section{References}

[1] G. A. R. Melo, "Notes on the systematics of the orchid-bee genus Eulaema (Hymenoptera, Apidae)," Revista Brasileira de Entomologia, vol. 58, no. 3, pp. 235-240, 2014.

[2] L. S. Kimsey, "An illustrated key to the genus Exaerete, with descriptions of male genitalia and biology (Hymenoptera: Euglossini, Apidae)," Journal of the Kansas Entomological Society, vol. 52, pp. 735-746, 1979.

[3] D. W. Roubik and P. E. Hanson, Orchid bees of tropical America: biology and field guide, Spanish/English edition. InBIO Press (Editorial INBio), Heredia, Costa Rica, 2004.

[4] C. A. Garófalo and J. G. Rozen Jr., "Parasitic behavior of Exaerete smaragdina with descriptions of its mature oocyte and larval instars (Hymenoptera: Apidae: Euglossini)," American Museum Novitates, vol. 3349, pp. 1-26, 2001.

[5] L. S. Kimsey, Systematics of bees of the genus Eufriesea, University of California Publications in Entomology, University of California, Berkeley, 1982.

[6] S. R. Ramírez, D. W. Roubik, C. Skov, and N. E. Pierce, "Phylogeny, diversification patterns and historical biogeography of euglossine orchid bees (Hymenoptera: Apidae)," Biological Journal of the Linnean Society, vol. 100, no. 3, pp. 552-572, 2010.

[7] M. S. Engel, "A new species of the cleptoparasitic orchid bee genus Exaerete from northern Venezuela (Hymenoptera: Apidae)," Entomologist's Monthly Magazine, vol. 154, no. 3, pp. 161-175, 2018.

[8] M. L. de Oliveira, "Notas taxonomicas sobre Exaerete (Hymenoptera: Apidae: Euglossina), com a descrição de uma nova espécie," Biota Neotropica, vol. 11, no. 1, pp. 129-132, 2011.

[9] D. W. Roubik, Ecology and natural history of tropical bees, Cambridge University Press, New York, 1989.

[10] J. D. Ackerman and D. W. Roubik, "Can extinction risk help explain plant-pollinator specificity among euglossine bee pollinated plants?” Oikos, vol. 121, no. 11, pp. 1821-1827, 2012.

[11] D. W. Roubik, "Ups and downs in pollinator populations: when is there a decline?" Conservation Ecology, vol. 5, no. 1, 2, 2001, http://consecol.org/vol5/iss1/art2.

[12] M. L. de Oliveira and A. Nemésio, "Exaerete lepeletieri (Hymenoptera: Apidae: Apini: Euglossina): a new cleptoparasitic bee from Amazonia," Lundiana, vol. 4, no. 2, pp. 117-120, 2003.

[13] D. W. Roubik, "Sibling species of Glossura and Glossuropoda in the Amazon region (Hymenoptera: Apidae: Euglossini)," Journal of the Kansas Entomological Society, vol. 77, no. 3, pp. 235-253, 2004.

[14] I. A. Hinojosa-Díaz and M. S. Engel, "Revision of the orchid bee subgenus Euglossella (Hymenoptera: Apidae), Part II: the viridis and mandibularis species groups," Journal of Melittology, no. 36, p. 1, 2014.

[15] M. Wikelski, J. Moxley, A. Eaton-Mordas et al., "Large-range movements of Neotropical orchid bees observed via radio telemetry," PLoS ONE, vol. 5, no. 5, p. e10738, 2010.

[16] D. W. Roubik, S. Sakai, and A. A. Hamid Karim, Pollination Ecology and the Rain Forest, vol. 174 of Ecological Studies Series, Springer-Verlag, New York, 2005.
[17] D. W. Roubik and J. D. Ackerman, "Long-term ecology of euglossine orchid-bees (Apidae: Euglossini) in Panama," Oecologia, vol. 73, no. 3, pp. 321-333, 1987.

[18] D. W. Roubik and J. T. Knudsen, "An embellishment that became a mutualism: inquiries on male bee tibial bouquets and fragrance-producing orchids in Panama and oceanic islands (Apidae: Apinae, Euglossini; Orchidaceae: Epidendroideae)," Flora, vol. 232, pp. 117-127, 2017.

[19] P. S. Padrón, D. W. Roubik, and R. P. Picón, "A preliminary checklist of the orchid bees (Hymenoptera: Apidae: Euglossini) of Ecuador," Psyche, vol. 2018, Article ID 2678632, 14 pages, 2018.

[20] D. W. Roubik, "100 species of meliponines (Apidae: Meliponini) in a parcel of western Amazonian forest at Yasuní Biosphere Reserve, Ecuador," in Pot-Pollen in Stingless Bee Melittology, P. Vit, S. R. M. Pedro, and D. W. Roubik, Eds., pp. 189-206, Springer Nature, New York, NY, USA, 2018. 


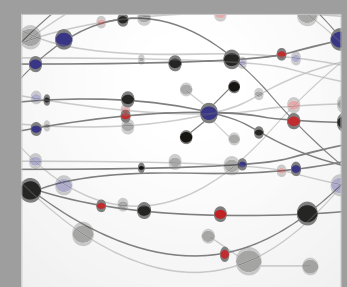

The Scientific World Journal
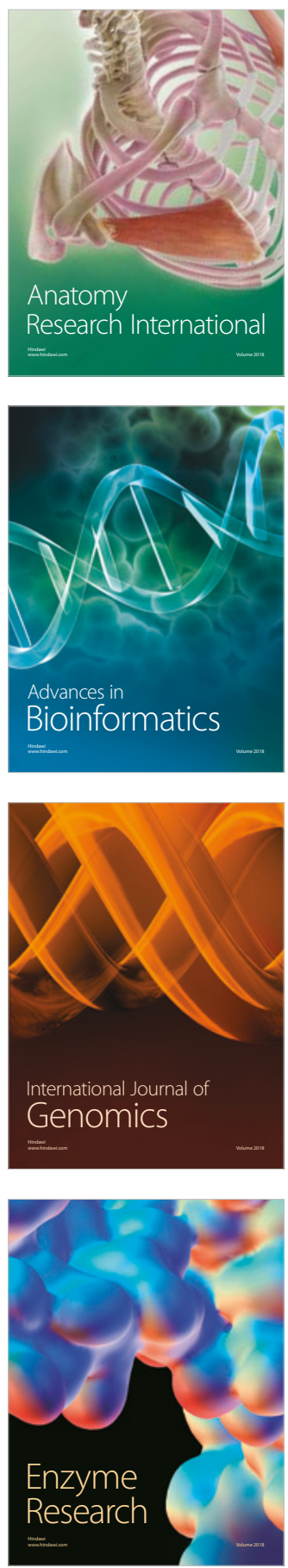
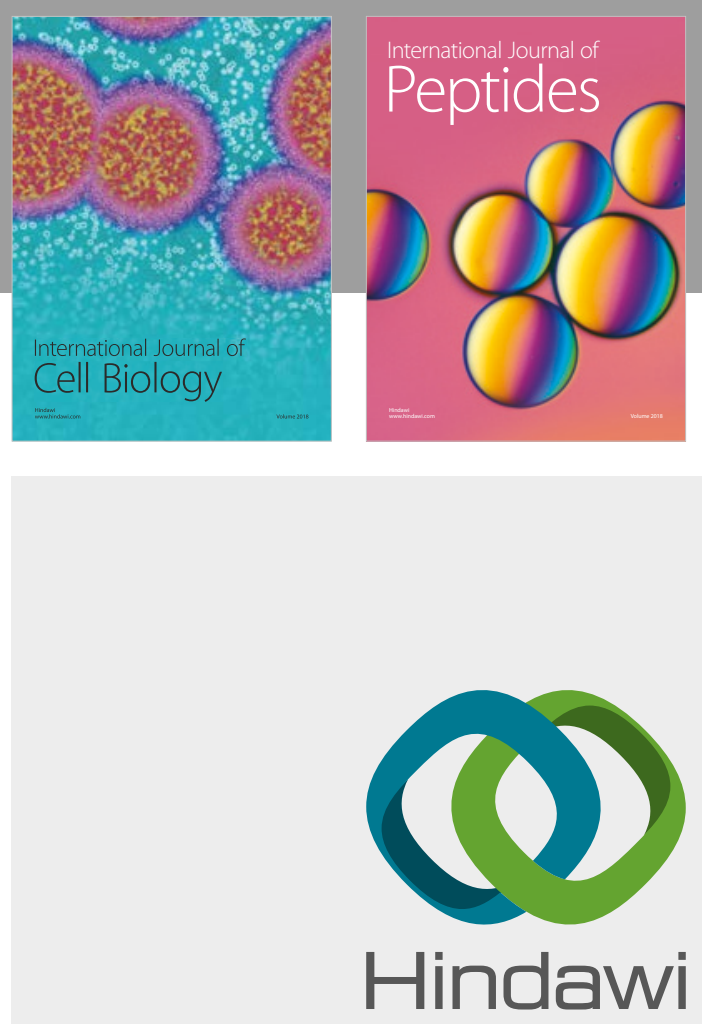

Submit your manuscripts at

www.hindawi.com
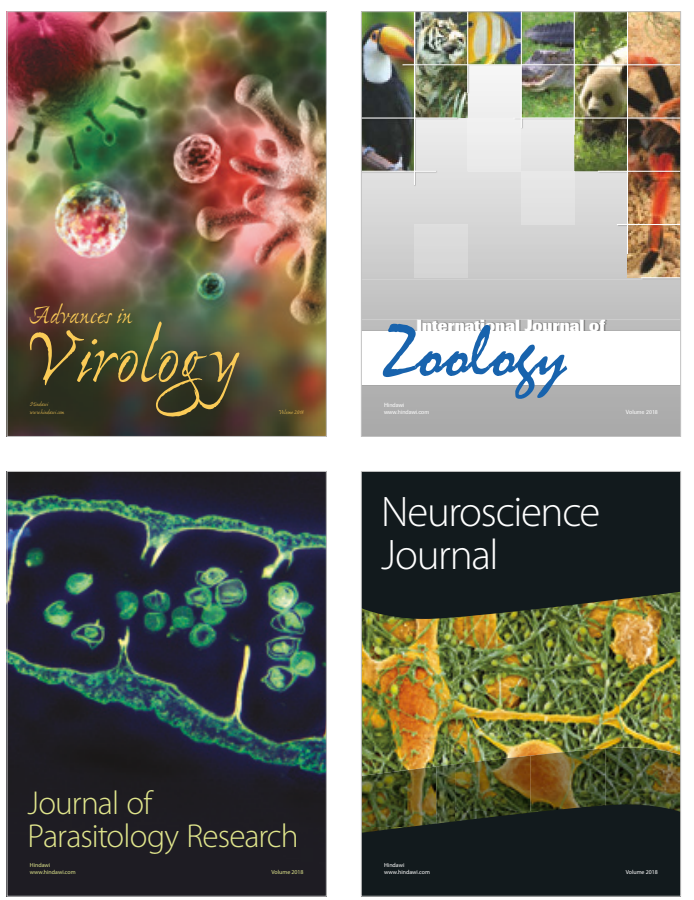
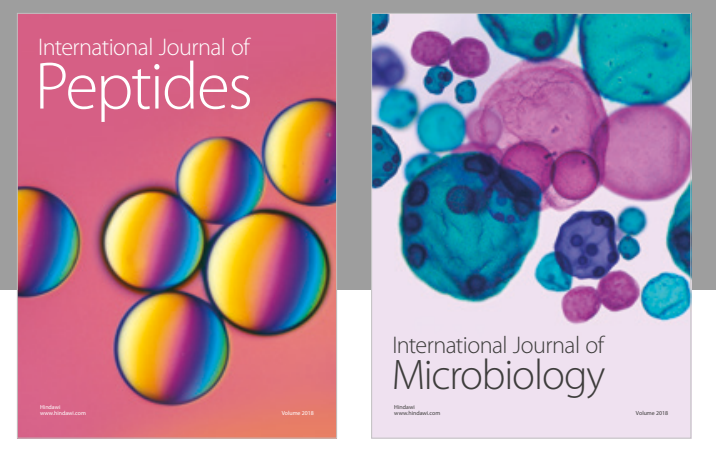

nternational Journal of Microbiology
Journal of
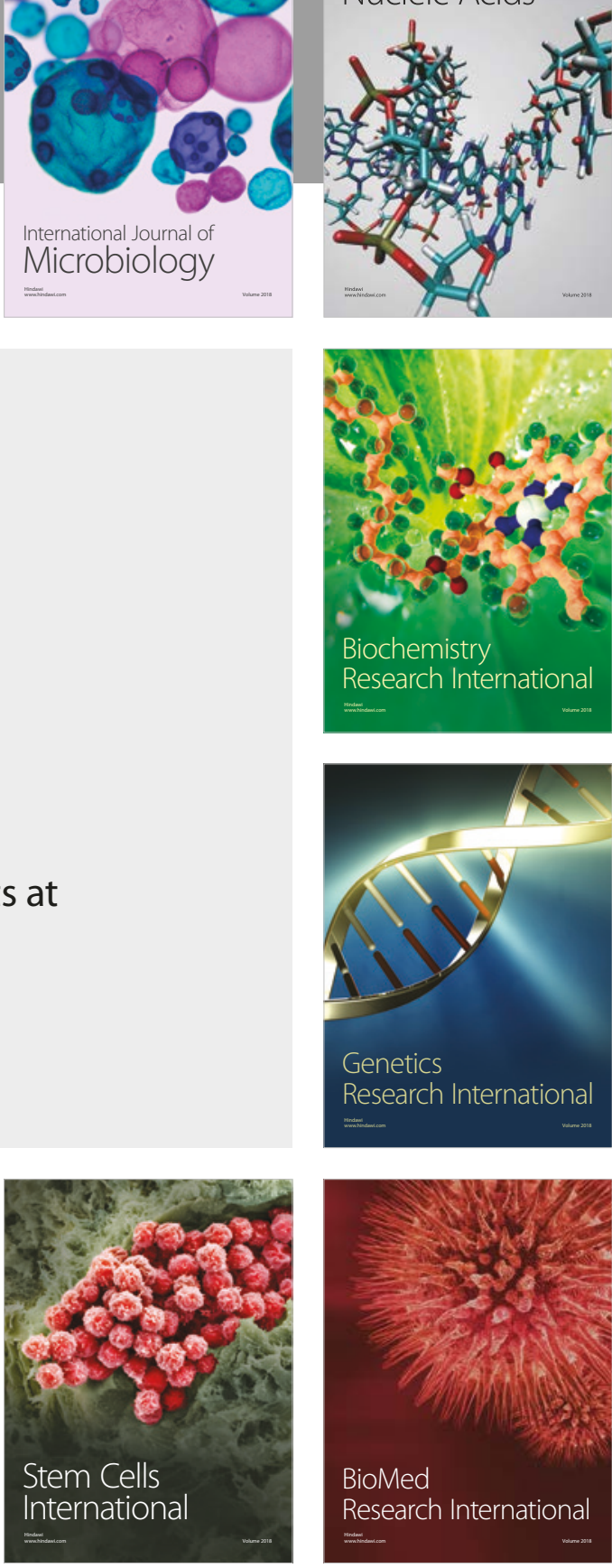
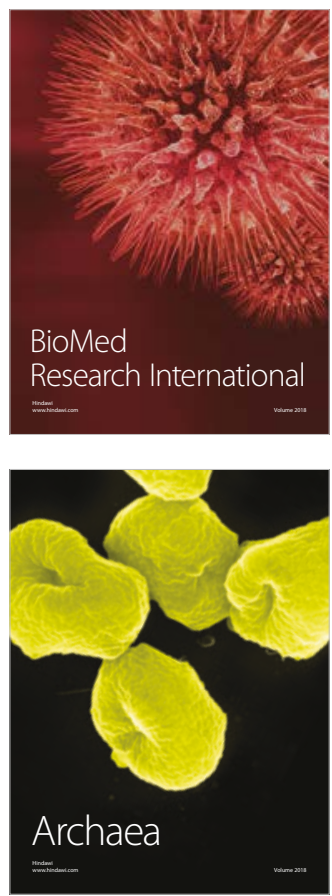